\title{
A case of resected primary pulmonary pleomorphic carcinoma with long-term survival after multidisciplinary treatment
}

\author{
Yoshihito lijima ${ }^{1 *}$ D, Yuki Nakajima', Hiroyasu Kinoshita', Yasuyuki Kurihara', Yu Nishimura², Toshihiko lizuka²,
} Hirohiko Akiyama' ${ }^{1}$ and Tomomi Hirata' ${ }^{1}$

\begin{abstract}
Background: Generally, primary pulmonary pleomorphic carcinoma is resistant to treatment and has a poor prognosis. We report a case of resected primary pulmonary pleomorphic carcinoma with long-term survival after multidisciplinary treatment.

Case presentation: A 74-year-old man with a history of emphysema, pneumoconiosis, and chronic bronchitis presented with left lung nodule and left adrenal tumor based on computed tomography. We suspected clinical T1bNOM1b, stage IVB lung cancer. Adrenalectomy of the left adrenal tumor yielded a definitive diagnosis of pleomorphic carcinoma. Chemotherapy was performed despite the spontaneous regression of lung lesions. Since lung lesions re-enlarged 11 months after adrenalectomy, the left lower lobe was partially resected followed by chemotherapy. The lung lesion was the primary lesion of the adrenal tumor. There was no recurrence 100 months after the lung resection.

Conclusions: The patient experienced long-term survival after multidisciplinary treatment. Both multidisciplinary treatment and immunological mechanisms caused spontaneous regression of the primary lesion.
\end{abstract}

Keywords: Lung cancer, Pleomorphic carcinoma, Multidisciplinary treatment, Long-term survival, Spontaneous regression

\section{Background}

The histological type pulmonary pleomorphic carcinoma (PPC) was first proposed in the WHO classification in 1999. It was defined as a poorly differentiated nonsmall cell carcinoma, namely squamous cell carcinoma, adenocarcinoma, or large cell carcinoma containing at least $10 \%$ or more spindle cells and/or giant cells, or a carcinoma consisting only of spindle or giant cell" [1]. Generally, primary pulmonary pleomorphic carcinoma is resistant to treatment and has a poor prognosis. We report a case of resected primary pulmonary pleomorphic carcinoma with long-term survival after multidisciplinary treatment.

\footnotetext{
* Correspondence: yoshihito@cancer-c.pref.saitama.jp

'Division of Thoracic Surgery, Saitama Cancer Center, 780 Komuro, Ina-machi, Kita adachi-gun, Saitama 362-0806, Japan

Full list of author information is available at the end of the article
}

\section{Case presentation}

A 74-year-old man presented with a left lung nodule and left adrenal tumor based on computed tomography (CT) and was referred to us. He had a history of emphysema, pneumoconiosis, and chronic bronchitis. He had a history of smoking with a Brinkman index of 750. Serum tumor markers including carcinoembryonic antigen, cytokeratin 19 fragment, and pro-gastrin-releasing peptide were within the normal ranges. Chest and abdominal CT showed a wellcircumscribed, 1.6- $\mathrm{cm}$ mass in the S6 segment of the left lower lobe (Fig. 1a) and a 3.5-cm mass in the left adrenal gland. Positron emission tomography (PET)-CT imaging revealed ${ }^{18} \mathrm{~F}$-fluorodeoxyglucose (FDG) accumulation of a maximum standardized uptake value (SUV max) of 3.88 and 6.14 in the lung nodule and adrenal mass, respectively. We suspected clinical T1bN0M1b, stage IVB lung cancer of the left lower lobe and performed bronchoscopy. We performed left adrenalectomy to obtain a definitive diagnosis. 


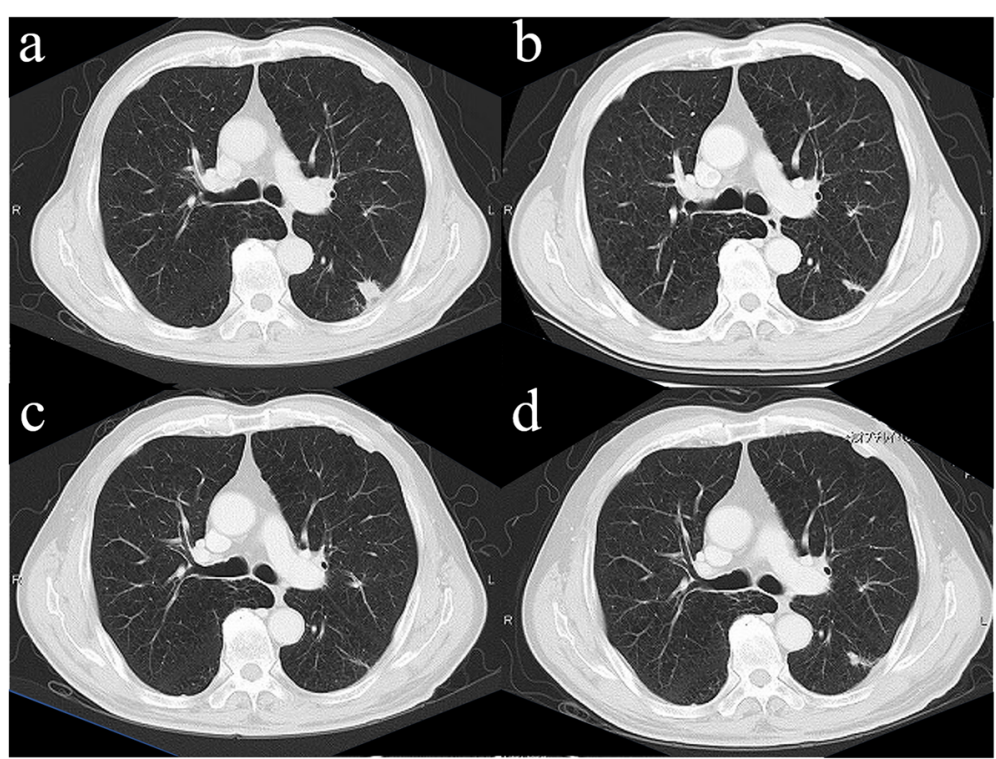

Fig. 1 Computed tomography (CT). a Chest CT showed a well-circumscribed, 1.6-cm mass in the $S 6$ segment of the left lower lobe. $\mathbf{b} C T$ performed before chemotherapy and 2 months after left adrenalectomy showed spontaneous regression of lung lesions. c After chemotherapy, the lung lesions became linear and nearly disappeared. $\mathbf{d}$ Lung lesions re-enlarged 11 months after adrenalectomy

Operation time and blood loss were $115 \mathrm{~min}$ and $56 \mathrm{ml}$, respectively. The left adrenal tumor was gray-white with a clear border of $3.5 \mathrm{~cm}$ consisting of solid, proliferative, short spindle cells without clear differentiation (Fig. 2a, b). Since a part of the tumor showed slight epithelial differentiation and most immunohistological epithelial markers were positive, metastatic cancer was considered. Immunohistochemical staining was positive for AE1/AE3, CAM5.2, epithelial membrane antigen (EMA), and vimentin but negative for thyroid transcription factor-1 (TTF-1), smooth muscle actin (SMA), desmin, and PE-10. Although it was TTF-1 negative and the lung lesion could not be determined as the primary lesion,

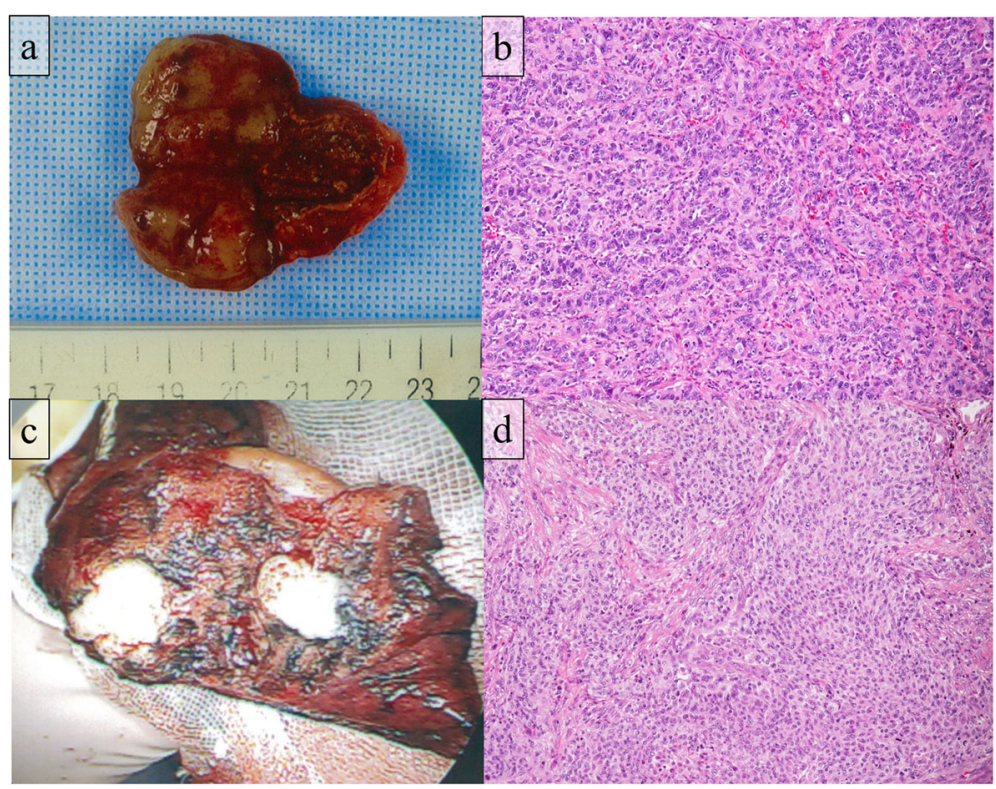

Fig. 2 Pathological findings. a Macroscopic findings of the adrenal tumor: the tumor was a 3.5-cm gray-white tumor with a clear border. b Microscopic findings of the adrenal tumor: the tumor consisted of solid, proliferative, short, spindle cells without clear differentiation. c Macroscopic findings of the lung tumor: the tumor was a 1.4-cm, solid, white tumor with a clear border. $\mathbf{d}$ Microscopic findings of the lung tumor: there was no clear keratinization, inter-tissue bridge, or ductal structure, and the findings were similar to those of adrenal tumors 
there was a high possibility of metastasis of the primary PPC. CT after left adrenalectomy showed spontaneous regression of the lung lesion (Fig. 1b). Therefore, the possibility of inflammatory changes in S6 lung nodules could not be ruled out. Moreover, the possibility of cTXNOM1b, stage IVA lung cancer of unknown origin remained. Subsequently, chemotherapy with cisplatin and docetaxel was administered according to adjuvant chemotherapy of nonsmall cell carcinoma regimen. Finally, two courses of chemotherapy were administered. Chemotherapy was discontinued after two courses at the patient's request due to nausea. After chemotherapy, the lung lesions became linear and nearly disappeared (Fig. 1c). Since lung lesions reenlarged 11 months after adrenalectomy (Fig. 1d), PET-CT was performed that showed an FDG accumulation with SUV max of 2.72 in the lung nodule. Eventually, the pulmonary nodule was determined to be the primary lesion, and we decided to resect it for definitive diagnosis. In the respiratory function test immediately before the operation, both the forced expiratory volume in $1 \mathrm{~s}(1.24 \mathrm{l})$ and the forced expiratory volume $1 \mathrm{~s}$ percent $(40.5 \%)$ were low. Due to high emphysema and poor lung function, we proposed a partial resection, and the patient agreed. Therefore, partial resection of the left lower lobe was performed. Operation time and blood loss were $60 \mathrm{~min}$ and $1 \mathrm{ml}$, respectively. Macroscopically, a solid white tumor with a clear border of $1.4 \mathrm{~cm}$ was observed (Fig. 2c). Histologically, there was no clear keratinization, inter-tissue bridge, or ductal structure, and the findings were similar to those of adrenal tumors (Fig. 2d). Immunohistochemical staining was positive for AE1/AE3, CAM5.2, EMA, and vimentin, and negative for TTF-1, SMA, desmin, and PE-10. The diagnosis was consistent with the primary lesions of adrenal tumors. Thus, three courses of chemotherapy with cisplatin and docetaxel were administered. There was no recurrence for 4 years and 3 months since the last treatment, and the patient was followed up at another hospital. After 8 years and 4 months since the lung resection, endocrine therapy was administered for the diagnosis of advanced prostate cancer. However, no recurrence of PPC was observed.

\section{Discussion}

PPC is a relatively rare form of lung cancer with a poor prognosis. There are few reported cases, and therefore, its outcome and prognostic factors are not elucidated. Fishback et al. reported a 5-year overall survival rate of $10 \%$ [2], but in recent reports, the 5-year overall survival rate was approximately $33-80 \%$ [3-6]. There were various reports on prognostic factors, but there is no unified view. Most of the items examined were based on the patient background (gender, age, smoking history, etc.) and pathological findings (pathological stage, lymph node metastasis, tumor size, etc.) [2-8]. However, the prognostic factors for stage IV PPC are not clear. There are six resected cases of stage IV PPC including this case (Table 1) [9-12]. All cases had no lymph node metastasis (N0) or metastasis to a single organ (M1b), and thus, surgical resection was effective in these cases.

PPC is generally refractory to treatment, such as chemotherapy and radiotherapy, but the most effective treatment is surgical resection. There is no evidence-based regimen because it is a rare pathological type. Postoperative adjuvant chemotherapy is often administered with platinum combination therapy, as in the case of other non-small cell lung cancer [13]. In addition, new anticancer agents such as molecular targeted therapeutic agents and immune checkpoint inhibitors may be effective. Zhao et al. reported a significant correlation between high microvessel density in tumor tissue and high tumor reduction rate with bevacizumab combined chemotherapy in advancedstage non-small cell lung cancer [14]. Bevacizumab combination therapy is expected to improve the therapeutic production phase. Moreover, the effective use of other molecular targeted therapeutic drugs, such as epithelial growth factor receptor (EGFR)-tyrosine kinase inhibitor (TKI) for cases with EGFR gene mutation [15], anaplastic lymphoma kinase (ALK)-TKI for ALK fusion genepositive cases [16], or immunity checkpoint inhibitors (ICI) for cases with high expression of programmed cell death ligand 1 case in PPC $[17,18]$ is expected to improve the treatment strategy for PPC.

Table 1 Resected cases of stage IV pulmonary pleomorphic carcinoma

\begin{tabular}{|c|c|c|c|c|c|c|c|c|c|c|c|}
\hline Case & Age & Sex & $\begin{array}{l}\text { Primary } \\
\text { site }\end{array}$ & $\begin{array}{l}\text { Tumor } \\
\text { diameter } \\
(\mathrm{cm})\end{array}$ & $\begin{array}{l}\text { Metastatic } \\
\text { organ }\end{array}$ & $\begin{array}{l}\text { Lymph node } \\
\text { metastases }\end{array}$ & Chemotherapy & Regimen & $\begin{array}{l}\text { Observation period } \\
\text { after surgery (years) }\end{array}$ & Outcome & Reference \\
\hline 1 & 71 & Male & $\mathrm{RL}$ & 7 & Brain & None & Pre & CBDCA+GEM & 7 & $\mathrm{RF}, \mathrm{A}$ & [9] \\
\hline 2 & 48 & Male & $\mathrm{RU}$ & 6.5 & Jejunum & None & None & - & 6 & $\mathrm{RF}, \mathrm{A}$ & [10] \\
\hline 3 & 63 & Male & LU & 7.3 & lleum & None & Post & CBDCA+PTX & 1 & $\mathrm{RF}, \mathrm{A}$ & [11] \\
\hline 4 & 69 & Male & $\mathrm{RU}$ & 4.8 & Stomach & None & None & None & 5 & $R F, A$ & [12] \\
\hline 5 & 62 & Male & LU & 3.3 & Stomach & None & None & None & 4 & $R F, A$ & [12] \\
\hline 6 & 74 & Male & $\mathrm{LL}$ & 1.4 & $\begin{array}{l}\text { Adrenal } \\
\text { gland }\end{array}$ & - & Pre, post & $\mathrm{CDDP}+\mathrm{DOC}$ & 8.5 & $\mathrm{RF}, \mathrm{A}$ & Our case \\
\hline
\end{tabular}

$R L$ right lower, $R U$ right upper, $L U$ left upper, $L L$ left lower, pre preoperative lung resection, post postoperative lung resection, $C B D C A$ carboplatin, $G E M$ gemcitabine, PTX paclitaxel, CDDP cisplatin, DOC docetaxel, $R F$ recurrence free, $A$ alive 
Several studies reported the spontaneous regression of tumors owing to an immune response triggered by CTguided nodal biopsy, transbronchial lung biopsy, or surgical treatment [19-21]. In particular, the regression of tumors triggered by radiation therapy outside the irradiation field is called an abscopal effect [22], and the combined use of ICI and radiation therapy has attracted attention in recent years [23]. In this case, as well as in previous reports $[20,21]$, spontaneous regression of the primary lesion was observed after resection of the adrenal metastasis suggesting that some immunological mechanisms were involved in cancer control in addition to multidisciplinary treatment. We hope that immunological mechanisms for cancer control other than the abscopal effect will be elucidated in the future.

\section{Conclusions}

The patient experienced long-term survival of the primary lung pleomorphic carcinoma. Both multidisciplinary treatment and immunological mechanisms caused spontaneous regression of the primary lesion of PPC.

\section{Abbreviations}

ALK: Anaplastic lymphoma kinase; CT: Computed tomography; EGFR: Epithelial growth factor receptor; EMA: Epithelial membrane antigen; FDG: ${ }^{18}$ F-Fluorodeoxyglucose; ICl: Immunity checkpoint inhibitors; PET: Positron emission tomography; PPC: Pulmonary pleomorphic carcinoma; SMA: Smooth muscle actin; SUV max: Maximum standardized uptake value; TKI: Tyrosine kinase inhibitor; TTF-1: Thyroid transcription factor-1

\section{Acknowledgements}

We would like to thank Editage (www.editage.jp) for the English language editing.

\section{Authors' contributions}

YI wrote the manuscript. The remaining authors contributed to the collection, analysis, and interpretation of data. All authors conceived the study, participated in its design and coordination, and helped to draft the manuscript. All authors have read and approved the final manuscript.

\section{Funding}

This study has not received any funding.

\section{Availability of data and materials}

The patient data for this case report will not be shared to ensure patient confidentiality.

\section{Ethics approval and consent to participate}

The publication of this case report was approved by the institutional ethics committee.

\section{Consent for publication}

The case report and publication process were explained to the patient, and he granted permission to publish the report.

\section{Competing interests}

The authors declare that they have no competing interests.

\section{Author details}

'Division of Thoracic Surgery, Saitama Cancer Center, 780 Komuro, Ina-machi, Kita adachi-gun, Saitama 362-0806, Japan. ²Division of Pathology, Saitama Cancer Center, Saitama, Japan.
Received: 22 November 2019 Accepted: 14 January 2020

Published online: 28 January 2020

\section{References}

1. Travis WD, Brambilla E, Burke AP, Marx A, Nicholson AG. Sarcomatoid carcinoma. WHO classification of tumors of the lung, pleura, thymus and heart. 4th ed. Lyon: International Agency for Research on Cancer; 2015. p. 88-90.

2. Fishback NF, Travis WD, Moran CA, Guinee DG Jr, McCarthy WF, Koss MN Pleomorphic (spindle/giant cell) carcinoma of the lung; a clinicopathologic correlation of 78 cases. Cancer. 1994;73:2936-45.

3. Yuki T, Sakuma T, Ohbayashi C, Yoshimura M, Tsubota N, Okita Y, et al. Pleomorphic carcinoma of the lung: a surgical outcome. J Thorac Cardiovasc Surg. 2007;134:399-404.

4. Venissac N, Pop D, Lassalle S, Berthier F, Hofman P, Mouroux J, et al. Sarcomatoid lung cancer (spindle/giant cells): an aggressive disease? J Thorac Cardiovasc Surg. 2007;134:619-23.

5. Yamamoto S, Hamatake D, Ueno T, Higuchi T, Hiratsuka M, Shiraishi T, et al. Clinicopathological investigation of pulmonary pleomorphic carcinoma. Eur J Cardiothorac Surg. 2007:32:873-6.

6. Mochizuki T, Ishii G, Nagai K, Yoshida J, Nishimura M, Tetsuya M, et al. Pleomorphic carcinoma of the lung: clinicopathologic characteristics of 70 cases. Am J Surg Pathol. 2008;32:1727-35.

7. Kamimura Y, Tanahashi M, Yukiue H, Suzuki E, Yoshii N, Kitazawa S, et al. Prognostic factors in surgically resected pulmonary pleomorphic carcinoma. J Jpn Assoc Chest Surg. 2018;32:556-63 (Japanese article with English abstract).

8. Okuda K, Oda R, Suzuki A, Sakane T, Kawano O, Hiroshi H, et al. Clinicopathological factors influenced the prognosis of surgically resected pulmonary pleomorphic carcinoma. J Thorac Dis. 2017;9:1295-302.

9. Yamnashi K, Marumo S, Miura K, Kawashima M. Long-term survival in a case of pleomorphic carcinoma with brain metastasis. Case Rep Oncol. 2014;7: 799-803.

10. Miura N, Mori R, Takenaka T, Yamazaki K, Momosaki S, Takeo S. Stage IV pleomorphic carcinoma of the lung without recurrence for 6 years: a case report. Surg Case Rep. 2017:3:36.

11. Kim MJ, Lee HN, Kim Jl, Kim GY. Pleomorphic carcinoma of the lung mimicking synchronous pulmonary adenocarcinoma and small bowel sarcoma. Ann Thorac Med. 2018;13:251-3.

12. Aokage K, Yoshida J, Ishii G, Takahashi S, Sugito M, Nishimura M, et al. Longterm survival in two cases of resected gastric metastasis of pulmonary pleomorphic carcinoma. J Thorac Oncol. 2008;3:796-9.

13. Bae HM, Min HS, Lee SH, Kim DW, Chung DH, Lee JS, et al. Palliative chemotherapy for pulmonary pleomorphic carcinoma. Lung Cancer. 2007; 58:112-5.

14. Zhao YY, Xue C, Jiang W, Zhao HY, Huang Y, Feenstra $K$, et al. Predictive value of intratumoral microvascular density in patients with advanced nonsmall cell lung cancer receiving chemotherapy plus bevacizumab. J Thorac Oncol. 2012;7:71-5.

15. Tamura $Y$, Fujiwara $Y$, Yamamoto $N$, Nokihira H, Horinouchi $H$, Kanda S, et al. Retrospective analysis of the efficacy of chemotherapy and molecular targeted therapy for advanced pulmonary pleomorphic carcinoma. BMC Res Notes. 2015:8:800

16. Lin L, Huang F, Chen F, He Y, Hu J, Cao X. Anaplastic lymphoma kinase (ALK)-rearranged pulmonary pleomorphic carcinoma successfully treated with crizotinib. J Int Med Res. 2018;46:3491-7.

17. Kanazu M, Uenami T, Yano Y, Nakatsubo S, Hosono Y, Ishijima M, et al. Case series of pleomorphic carcinomas of the lung treated with nivolumab. Thorac Cancer. 2017:8:724-8.

18. Forde PM, Chaft JE, Smith KN, Anagnostou V, Cottrell TR, Hellmann MD, et al. Neoadjuvant PD-1 blockade in resectable lung cancer. New Eng J Med. 2018;378:1976-86.

19. Iwanaga T. Studies on cases of spontaneous regression of cancer in Japan in 2011, and of hepatic carcinoma, lung cancer and pulmonary metastases in the world between 2006 and 2011. Jpn J Cancer Chemother. 2013;40: 1475-87.

20. Cole WH. Efforts to explain spontaneous regression of cancer. J Surg Oncol. 1981;17:201-9.

21. Muranishi Y, Ueshima Y, Hasegawa K, Shiotsu S, Takumi C, Hiraoka N. Spontaneous regression of pleomorphic lung carcinoma. AJRS. 2012;1:498501 (Japanese article with English abstract). 
22. Mole RH. Whole-body irradiation; radiobiology or medicine? $\mathrm{Br} J$ Radiol, 1953;26:234-41.

23. Postow MA, Callahan MK, Barker CA, Yamada Y, Yuan J, Shigehisa K, et al. Immunologic correlates of the abscopal effect in a patient with melanoma. N Engl J Med. 2012;366:925-31.

\section{Publisher's Note}

Springer Nature remains neutral with regard to jurisdictional claims in published maps and institutional affiliations.

\section{Submit your manuscript to a SpringerOpen ${ }^{\circledR}$} journal and benefit from:

- Convenient online submission

- Rigorous peer review

- Open access: articles freely available online

- High visibility within the field

- Retaining the copyright to your article

Submit your next manuscript at $\boldsymbol{\nabla}$ springeropen.com 